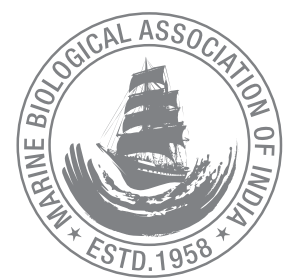

\title{
Transcriptomic approach to study salinity tolerance in euryhaline cichlid, Etroplus suratensis (Bloch, 1790)
}

\author{
T. V. Arun Kumar', M. A. Pradeep ${ }^{1 *}$, Esha Arshad' and K. K. Vijayan ${ }^{2}$ \\ IICAR- Central Marine Fisheries Research Institute, Kochi-682 018, Kerala, India. \\ ${ }^{2}$ ICAR Central Institute of Brackishwater Aquaculture, Chennai-600 028, Tamil Nadu, India. \\ *Correspondence e-mail: drpradeepma@gmail.com
}

Received: 25 June 2020 Accepted: 20 July 2020 Published: 25 July 2020

Original Article

\begin{abstract}
Increasing levels of salinity in coastal and freshwater environments as a result of rise in sea level is linked to climate change and it impacts fish growth adversely. Etroplus suratensis (Pearlspot) is the largest species among the indigenous cichlid which is essentially brackishwater fish that has become naturally acclimated to freshwater. Understanding the basis of tolerance and acclimatization to increased environmental salinity and freshwater condition can help the regional aqua-farmers to mitigate predicted impacts of climate change in that region. Technically the last decade contributed many methodologies to understand the salinity adaptation mechanisms; suppression subtractive hybridization (SSH) library generation being one of them. In this study we performed SSH technique to identify genes involved in salinity adaptation and osmoregulation in gills of $E$. suratensis, generating from fishes exposed to seawater (SW-36\%) as compared to freshwater (FW-0 $\%$ ). Here, SSH was used to identify alterations in gene transcription of $E$. suratensis after exposure to $36 \%$. A random 105 clones were selected and sanger sequenced from the subtractive c-DNA libraries which gave a total of 80 gene fragment sequences. Sequencing analysis and homology searches showed that these EST's represented 68 unique gene and 12 duplicates. Of the 68 unique genes, 62 shared high homology with fish genes of known functions including immunity, stress, cellular process, cytoskeleton and transporter.
\end{abstract}

Gene expression profile of the selected 10 EST's acclimated to SW and FW conditions from SSH library was carried out. The candidate genes identified in $E$. suratensis gills provided valuable information to study and understand new functional genes that act as osmosensors in osmotic regulations.

Keywords: Euryhaline, salinity tolerance, SSH, c-DNA library, gene expression profile

\section{Introduction}

Etroplus suratensis (Pearl spot), brackishwater euryhaline fish included in the family cichlidae inhabits in both brackish and freshwater ecosystems (Padmakumar et al., 2012). It can withstand wide range of temperature and salinity conditions as it has highly efficient cellular stress response mechanism and osmoregulatory mechanisms (Chandrasekar et al., 2014). Although osmoregulation in fish is mediated by a group of organs including the intestine and kidney, gill is the major organ responsible for balancing ion movement (Hirose et al., 2003). Ability to adapt to wide salinity regimens increases the profitability of $E$.suratensis in aquaculture. Seasonal fluctuation in salinity is one of the main constraints for culturing this 
fish in inland saline soil. Although the fish completes its life cycle either in brackish or in freshwater, the former being the potential source of seeds for propagation of its culture practices in fresh and inland saline waters in spite of the fact that fry and fingerlings cannot withstand the salinity stress while transferring directly from saltwater to freshwater (Menon et al., 1959). Like any other teleost species, the gills of $E$. suratensis are a multifunctional organ responsible for gaseous exchange, osmoregulation, acid-base balance, ammonia excretion, hormone production, modification of circulating metabolites and immune defence.

Coastal and estuarine habitats are one of the most dynamic ecosystems owing to the diurnal and seasonal environmental fluctuations which cause significant physiological stress on the organisms. Survival of these animals in such a challenging environment depends on its capability to acclimatize to such variations. Teleosts that are euryhaline have osmoregulatory genes that maintain homeostasis mainly by the epithelial cells in the gills; it is believed that these cells have the ability to withstand severe osmotic stress. While adapting from BW to SW or FW the cells in the gill epithelium are regularly remodelled for extensive ion transport and permeability (Arun Kumar et al., 2020). The survival of teleost during hyperosmotic stress is carried out by upregulation of several genes that regulates the physiological mechanism of acclimatization such as CFTR, $\mathrm{Na}^{+} / \mathrm{K}^{+} / 2 \mathrm{Cl}$ (NKCC) (Marshall and Singer, 2002; Evans et al., 2005). In this adaptive process, two consecutive phases occur: an initial period characterized by changing osmotic variables, followed by a chronic regulatory period, when these variables reach a new homeostasis (Holmes and Donaldson, 1969; Maetz, 1974).

Euryhaline teleosts have adaptive capacity to withstand a broad range of salinities through efficient osmoregulation in order to maintain homeostasis. In the following investigation, we apply high-throughput transcriptomics methods to euryhaline $E$. suratensis to pave the way towards a systems biology approach for studying osmoregulation. Therefore, the aim of the present study was to describe and analyse the alterations and the compensatory mechanisms occurring in the branchial osmoregulatory organ, the gills of $E$. suratensis exposed and acclimated to a range of salinities $(0 \%, 18 \%$ and $36 \% 0$ ). Use of techniques like suppression subtractive hybridization (SSH) enables us to identify genes which are differentially expressed in one population and absent in the other (Diatchenko et al., 1996; Xie et al., 2010). In this study, SSH was used to bio-prospect the array of genes involved in combating salinity stress. Understanding the mechanisms by which these organisms adapt to the local stressor is important to gain a better perspective of their physiological tolerance limits as well.

\section{Material and methods}

\section{Experimental animals}

E. suratensis ( $\mathrm{n}=75$ and $12 \pm 2 \mathrm{~cm}$ length) were obtained from pearlspot farms in Ernakulam, Kerala, India and acclimated in the laboratory for 15 days in one tonne capacity fibre reinforced plastic tanks containing $500 \mathrm{~L}$ water with continuous aeration. (Salinity: $16 \%$, temperature: $28 \pm 1^{\circ} \mathrm{C}$ and pH: $7.8 \pm 0.4$ (as per the parameters existed in the collected pond)).

\section{Salinity tolerance experiment and tissue collection}

After acclimatization, the fishes were divided into 3 groups of 18 fishes in each group. Each group was maintained in triplicates with 6 fish in each replicate. The fishes were maintained in $250 \mathrm{~L}$ experimental glass tanks. First group was exposed to salinity $0 \%$ (fresh water, FW); the second group to $36 \%$ (sea water, SW) and the third group were exposed to $18 \%$ ( brackishwater, BW) for 21 days. The required salinity was attained by steadily increasing/ decreasing the salinity by 2-3\%o every day by adding SW/FW. After attaining the respective salinity, the fishes were maintained in that salinity for four weeks. At the end of the experiment, fishes were anesthetised with 2-phenoxy ethanol $(1 \mathrm{~mL} / \mathrm{L})$ and gill samples were excised and were immediately transferred to RNAlater ${ }^{\mathrm{TM}}$ (Ambion) and stored at room temperature for 1 $\mathrm{hr}$ and then at $-80^{\circ} \mathrm{C}$ until RNA isolation.

\section{RNA and mRNA Isolation}

Total-RNA was extracted according to standard TRIZOL RNA isolation protocol (Life Technologies, Inc., Grand Island, NY) from gills of FW adapted and SW adapted animals. Isolated total RNA was quantified by Bio photometer plus (Eppendorf, Germany) and its integrity was checked in $1.5 \%$ agarose gel. The poly (A) ${ }^{+}$mRNA was isolated from the total-RNA using a poly (dT) resin (Qiagen, Hilden, Germany) as per the recommended guidelines. A total of $2 \mu \mathrm{g}$ purified mRNA was used for the synthesis of CDNA and SSH.

\section{Suppression subtractive hybridization}

Poly (A)+ mRNA from SW adapted tissues was used as the 'tester' while poly $(A)^{+}$mRNA from FW tissues served as the 'driver' (forward SSH library). Differentially expressed cDNAs were present in the tester CDNA, but were either absent or present only in very low levels in the driver CDNAs. Construction of the forward library was performed according to SSH procedure using a PCR-select cDNA subtraction kit (Clontech, Palo Alto, CA). Equal amounts of poly $(A)^{+}$mRNA from each of the tester and driver populations were converted to double-stranded CDNA by reverse transcription, 
followed by digestion with Rsal to produce shorter blunt-ended fragments. The digested tester CDNA was subdivided into two populations, each of which was ligated with a different adaptor from those provided in the CDNA subtraction kit. Following ligation, two hybridization steps were performed. For the first hybridization, an excess of driver was added to each tester, denatured, and allowed to anneal. The target sequences in the tester were then significantly prepared for identification of differentially expressed genes. In the second hybridization step, the two reaction products from the first hybridization were mixed with each other and with fresh denatured driver CDNA. The population of normalized and subtracted single-stranded target cDNA were annealed with each other, forming double-stranded hybrids with different adaptor sequences at their $5^{\prime}$ ends. The adaptor ends were then filled with DNA polymerase and the subtracted molecules were specifically amplified by 'nested PCR' using adaptor-specific primer pairs.

\section{Construction of subtracted cDNA libraries}

The subtracted target CDNAs (the nested PCR products) were ligated with the pJET 1.2 Blunt cloning vector (Thermo Scientific, USA) using T4 DNA ligase and transformed into maximum efficiency Escherichia coli TOP 10 competent cells (Invitrogen). The transformed bacteria were plated onto LB agar plates containing ampicillin, and were then incubated overnight at $37^{\circ} \mathrm{C}$. Recombinant colonies were all selected and screened for positive clones and were cultured in LB broth containing ampicillin. Plasmid extraction was performed using Gene JET plasmid miniprep kit (Thermo Scientific, USA) and sequenced. The sequences were contig aligned using SeqMan software. The contigs were BLAST analysed for its homology with the already present sequences in the NCBI database.

\section{CDNA synthesis and Quantitative Real Time PCR for SSH EST validation}

Gene expression profile of the selected EST's was analysed using Light Cycler 96 (Roche, Switzerland) Real time Thermal cycler. Quantitative validation of the genes under different salinity $(0 \%$, $18 \%$ and $36 \%$ ) was carried out. Expression patterns were analysed on 10 genes from the SSH forward library. The RNA samples isolated from the gills of acclimatised fishes were quantified spectrophotometrically (Eppendorf, Germany) and the integrity of the samples were checked in 1.5\% Agarose gel. Quantified RNA was treated with RNase free DNase I $(1 \mathrm{U} / \mu \mathrm{g}$ RNA, Fermentas) to remove the genomic DNA contamination. First strand CDNA was synthesised using iscript CDNA synthesis kit (Bio-Rad, USA). The resultant CDNA was diluted and used as template in $25 \mu \mathrm{l} P C R$ reaction mix with $\mathrm{Q} Q$ SYBR green super mix (Bio-Rad, USA) and gene specific primers (Table 1) designed from the selected EST's obtained after SSH. Expression level of the selected genes at $36 \%$ and $0 \%$ was normalised with

Table 1. List of primers used for the quantitative validation of selected salinity stress induced genes in $E$. suratensis gill tissue.

\begin{tabular}{|c|c|c|c|c|}
\hline SL. No & Gene & Primer & Sequence $\left(5^{\prime}-3^{\prime}\right)$ & Product size (bp) \\
\hline 1. & ADP-ATP Translocase2 & $\begin{array}{l}\text { ADP-ATP Trans QF } \\
\text { ADP-ATP Trans QR }\end{array}$ & $\begin{array}{l}\text { 5'-TGTTGCTGGCCTGACTTCAT-3' } \\
\text { 5'-TGATGTCAGCTCCTTTGCGT-3' }\end{array}$ & $85 \mathrm{bp}$ \\
\hline 2. & Aldo-keto reductase & $\begin{array}{l}\text { Aldo-keto QF } \\
\text { Aldo-keto QR }\end{array}$ & $\begin{array}{l}\text { 5'-TCCCCAGCTCAGATTCTCCT-3' } \\
\text { 5'-TGCGGGATTCTGTCACACTC-3' }\end{array}$ & 79 bp \\
\hline 3. & Bactericidal permeability increasing protein & $\begin{array}{l}\text { RbBPI/LBPI BP QF } \\
\text { RbBPI/LBPI BP QR }\end{array}$ & $\begin{array}{l}\text { 5'-GCTCACCAGTGAACCTGTCA-3' } \\
\text { 5'-CATGGTGAAAGGCTGGGACT-3' }\end{array}$ & $120 \mathrm{bp}$ \\
\hline 4. & $\alpha$ Enolase & $\begin{array}{l}\text { Enolase QF } \\
\text { Enolase QR }\end{array}$ & $\begin{array}{l}\text { 5'-CAGTCACAGAGTCCCTGCAG-3' } \\
\text { 5'-GTGCAGAGCCCAACAACAAG-3' }\end{array}$ & $124 \mathrm{~b}$ \\
\hline 5. & HSP 90 & $\begin{array}{l}\text { HSP } 90 \text { QF } \\
\text { HSP } 90 \text { QR }\end{array}$ & $\begin{array}{l}\text { 5'-GTGGAGAAGGAGCGTGACAA-3' } \\
\text { 5'-AGCCCCCGTCCTCTATCTTT-3' }\end{array}$ & 112 bp \\
\hline 6. & Inositol mono-phosphatase1 & $\begin{array}{l}\text { IMP QF } \\
\text { IMP QR }\end{array}$ & $\begin{array}{l}\text { 5'- TTGGAGTTTGGCGTGGTGTA-3' } \\
\text { 5'-GGCTCATCGTCACAGAAAGC-3' }\end{array}$ & $86 \mathrm{bp}$ \\
\hline 7. & Iso-citrate dehydrogenase & $\begin{array}{l}\text { Iso-citrate QF } \\
\text { Iso-citrate QR }\end{array}$ & $\begin{array}{l}\text { 5'-GCCACCATTACACCTGACGA-3' } \\
\text { 5'-TTCCTGATGGTTCCGTTGGG-3' }\end{array}$ & $83 \mathrm{bp}$ \\
\hline 8. & L-rhamnose binding lectin & $\begin{array}{l}\text { L-rhamnose QF } \\
\text { L-rhamnose QR }\end{array}$ & $\begin{array}{l}\text { 5'-GCTGATGCTGAGCGTTTCTG-3' } \\
\text { 5'-TGAAGGTGTACTCAGTTGTGCT-3' }\end{array}$ & $80 \mathrm{bp}$ \\
\hline 9. & Serine/threonine-protein phosphatase & $\begin{array}{l}\text { Serine/threonine QF } \\
\text { Serine/threonine QF }\end{array}$ & $\begin{array}{l}\text { 5'-TGCCTCAGAAGAATGCAGCA-3' } \\
\text { 5'-TGGTCTCTTGTCACGCTCAC-3' }\end{array}$ & 89 bp \\
\hline 10. & Sodium-coupled neutral amino acid transporter & $\begin{array}{l}\text { Sodium NAAT QF } \\
\text { Sodium NAAT QR }\end{array}$ & $\begin{array}{l}\text { 5'-TGCCCTCTTCGGATACCTGA-3' } \\
\text { 5'-GAGCACAACAGGGACGGTAA-3' }\end{array}$ & $148 \mathrm{bp}$ \\
\hline 11. & 18s rRNA & $\begin{array}{l}\text { 18S rRNA qF } \\
18 S \text { rRNA qR }\end{array}$ & $\begin{array}{l}\text { 5'-GGACACGGAAAGGATTGACAG-3' } \\
\text { 5'-GTTCGTTATCGGAATTAACCAGAC -3' }\end{array}$ & $140 \mathrm{bp}$ \\
\hline
\end{tabular}


expression level of $18 \%$ taken as control. The 18 s ribosomal gene of $E$. suratensis was chosen as an internal reference gene for determining the efficiency of RT amplification in different reactions using the method explained by Pfaffl (2001). qPCR amplification was carried out using the following programme: $94^{\circ} \mathrm{C}$ for $3 \mathrm{~min}$ followed by $45 \mathrm{cycles}$ at $94^{\circ} \mathrm{C}$ for $10 \mathrm{sec}, 60^{\circ} \mathrm{C}$ for $30 \mathrm{sec}$ and $72^{\circ} \mathrm{C}$ for $20 \mathrm{sec}$ and final melt curve starting from $99^{\circ} \mathrm{C}$ to $55^{\circ} \mathrm{C}, 0.5^{\circ} \mathrm{C}$ decrease in every 10 second was carried out to ensure that a specific product was amplified. All real time PCR experiments were carried out with biological triplicates in ROCHE (Switzerland) light cycler 96. PCR conditions were standardised for both the house keeping gene and the selected genes. The relative expression is determined by the formulae.

$$
\begin{aligned}
& \text { Expression Ratio }=\left\{\left(\mathrm{E}_{\text {target }}\right)^{\Delta C \mathrm{Ct}} \text { target }(\text { Control-Sample })\right\} / \\
&\left\{\left(\mathrm{E}_{\mathrm{ref}}\right)^{\Delta \mathrm{ct}}\right. \text { ref } \\
&\text { refontrol-Sample })\}
\end{aligned}
$$

Where $E_{\text {target }}$ and $E_{\text {ref }}$ are the PCR efficiency of the target and reference gene respectively and $C_{t}$ is the cycle threshold. The relative quantification results were expressed as the fold change in levels of the gene expression and statistical analysis of the data for comparison was carried out by one-way ANOVA and the values with $p<0.05$ were considered significant.

\section{Results}

\section{Salinity tolerance}

There was no mortality associated with acclimation of BW $E$. suratensis to FW and SW. After attaining the respective salinity, the fishes were maintained in that salinity for four weeks.

\section{Construction of subtracted cDNA library enriched for salinity induced genes}

The methodology that we used here was suppression subtractive hybridization, SSH (Diatchenko et al., 1999) for the identification of genes that were expressed during SW acclimation in gill epithelial cells of euryhaline $E$. suratensis. A subtracted CDNA library enriched for salinity induced genes was constructed as given in the methodology and the obtained clones were screened by colony PCR to identify individual clones out of which 105 clones were selected and Sanger sequenced.

The forward SSH CDNA libraries generated multiple colonies, representing upregulated genes respectively in the gill tissue at SW $(36 \%$ o) of $E$. suratensis with insert size varying from $250-650 \mathrm{bp}$. Clustering of the EST's generated 12 contigs and 68 singletons from the SSH cDNA library. SSH clones were grouped into putative functions based on the predicted functional category by BLAST analysis for the clones obtained from the c-DNA library (Table 2). One-fourth of the genes obtained were unknown which had no similarities with already submitted sequences (Fig. 1\&2). Inositol monophosphatase 1 (IMPA1), Isocitrate dehydrogenase, Sulfide-quinone oxidoreductase, Sodium-coupled neutral amino acid transporter 2 (solute carrier protein), HSP 90, ADP-ATP translocase 2 etc. were some of the genes which were related to salinity tolerance. For instance, such approaches have revealed a major role of the Inositol biosynthesis pathway which converts Glucose-6-phosphate to the compatible osmolytes myo-inositol that protects cells from osmotic stress, studies reveal that these are upregulated during salinity stress. This pathway is critical for maintaining cellular inorganic ion homeostasis during acute salinity stress. Some of the genes responsible for oxidative stress were also identified which included -Enolase, NADH Ubiquinone

Table 2. List of identified genes / proteins from SSH CDNA library constructed from E. suratensis gill tissue exposed to $36 \%$ (SW) salinity.

\begin{tabular}{lllll}
\hline Clone ID & Putative gene/Category & Homolog Species & E-Value & Accession No: \\
\hline SSH\#1_2 & GTP binding Protein 1 (gtpbp1) & Mylandia zebra & $3 \mathrm{e}-65$ & MN747809 \\
\hline SSH\#3_5 & H-2 class I histocompatibility antigen & Haplochromis burtoni & $1 \mathrm{e}-69$ & MN747811 \\
\hline SSH\#4_3 & Cytochrome P450 1A gene (CYP1A) & Oreochromis niloticus & 9e-92 & MN747812 \\
\hline SSH\#6_4 & Major histocompatibility complex class I-related gene & Stegastes partitus & 2e-62 & MN747813 \\
\hline SSH\#7_2 & Lysine-specific demethylase 6B & Pundamilia nyererei & 4e-99 & MN747814 \\
\hline SSH\#10_1 & Connector enhancer of kinase suppressor of Ras 1 (cnksr1) & Oreochromis aureus & 8e-66 & MN747822 \\
\hline SSH\#11_1 & Elongation factor 2 & Oreochromis aureus & 9e-96 & MN747823 \\
\hline SSH\#12_1 & Multiple C2 and transmembrane domain-containing protein 2 & Oreochromis aureus & 1e-80 & MN747824 \\
\hline SSH\#13_1 & Inositol monophosphatase 1protein IMPA 1 & Oreochromis aureus & 2e-92 & MN747825 \\
\hline SSH\#14_1 & Keratin, type I cytoskeletal 13 & Gouania willdenowi & 1e-48 & MN821124 \\
\hline SSH\#15_1 & Isocitrate dehydrogenase, mitochondrial & Oreochromis mossambicus & 1e-105 & MN821125 \\
\hline SSH\#17_1 & Keratin, type II cytoskeletal 8 & Oreochromis aureus & 3e-132 & MN821126 \\
\hline SSH\#18_1 & Threonine-rich GPI-anchored glycoprotein & Oreochromis niloticus & 5e-08 & MN886234 \\
\hline SSH\#19_1 & Cut like homeobox 1 (cux1) & Lates calcarifer & 4e-94 & MN821127 \\
\hline SSH\#20_1 & Serine/threonine-protein phosphatase & Oreochromis aureus & 4e-58 & MN821128 \\
\hline
\end{tabular}




\begin{tabular}{|c|c|c|c|c|}
\hline SSH\#21_1 & Leukocyte surface antigen CD53 & Archocentrus centrarchus & $3 e-39$ & MN821129 \\
\hline SSH\#22_1 & Cyclin-L1 & Lates calcarifer & $2 \mathrm{e}-36$ & MN821130 \\
\hline SSH\#23_1 & B-cell lymphoma 6 protein & Archocentruscentrarchus & $1 e-100$ & MN821131 \\
\hline SSH\#24_1 & Sodium-coupled neutral amino acid transporter 2 & Archocentrus centrarchus & $9 e-81$ & MN821132 \\
\hline SSH\#25_1 & Sulfide:Quinone oxidoreductase (sqor) & Amphiprion ocellaris & $2 \mathrm{e}-30$ & MN821133 \\
\hline SSH\#27_1 & Meteorin like protein & Oreochromis aureus & $4 e-94$ & MN821134 \\
\hline SSH\#28_1 & NADH ubiquinone oxidoreductase subunit B1 & Cyprinodon variegatus & $4 e-33$ & MN821135 \\
\hline SSH\#29_1 & 1,25-dihydroxyvitamin D(3) 24-hydroxylase, mitochondrial & Archocentrus centrarchus & $2 \mathrm{e}-77$ & MN821136 \\
\hline SSH\#30_1 & Heat shock protein $90 \mathrm{kDa}$ & Pundamilia nyererei & $3 e-54$ & MN821137 \\
\hline SSH\#33_1 & Microtubule-associated protein tau-like & Lates calcarifer & $3 e-59$ & MN821138 \\
\hline SSH\#36_1 & ZP domain-containing protein & Haplochromis burtoni & $2 \mathrm{e}-73$ & MN833169 \\
\hline SSH\#37_1 & General transcription factor IIF subunit 1 (gtf2f1) & Archocentrus centrarchus & $2 \mathrm{e}-23$ & MN893239 \\
\hline SSH\#38_1 & Basic helix-loop-helix family member E40 & Sparus aurata & $2 \mathrm{e}-77$ & MN833213 \\
\hline SSH\#39_1 & Adhesion G-protein coupled receptor G-5 & Oreochromis niloticus & $1 e-56$ & MN839977 \\
\hline SSH\#42_1 & Cyclic AMP-dependent transcription factor ATF- 4 & Stegastes partitus & $1 e-64$ & MN839978 \\
\hline SSH\#43_1 & Histone-lysine N-methyltransferase 2B & Archocentrus centrarchus & $4 e-17$ & MN893240 \\
\hline SSH\#46_1 & NLRC3-like protein & Archocentrus centrarchus & $5 e-56$ & MN839979 \\
\hline SSH\#50_1 & Oxysterol-binding protein-related protein 7 & Archocentrus centrarchus & $2 \mathrm{e}-47$ & MN854086 \\
\hline SSH\#51_1 & Muscle blind-like protein 1 variant & Oreochromis aureus & $7 e-81$ & MN854087 \\
\hline SSH\#52_1 & ADP-ATP translocase 2 & Lates calcarifer & $5 e-77$ & MN854088 \\
\hline SSH\#54_1 & MHC class I alpha antigen & Sphaeramia orbicularis & $7 e-27$ & MN854090 \\
\hline SSH\#55_1 & Nidogen 1 & Archocentrus centrarchus & $2 \mathrm{e}-40$ & MN854091 \\
\hline SSH\#58_1 & Muscle M-line assembly protein & Oreochromis niloticus & $5 e-51$ & MN854092 \\
\hline SSH\#61_1 & Damage-specific DNA binding protein (ddb1) & Archocentrus centrarchus & $2 \mathrm{e}-70$ & MN747815 \\
\hline SSH\#64_1 & Protein FAM83G & Oreochromis aureus & $5 e-37$ & MN854095 \\
\hline SSH\#69_1 & RbBPILBP1 mRNA for bactericidal permeability-increasing protein & Oplegnathus fasciatus & $9 e-41$ & MN886235 \\
\hline SSH\#72_1 & MHC class II Histocompatibility antigen & Sander lucioperca & $2 \mathrm{e}-39$ & MN938442 \\
\hline SSH\#74_1 & RNA polymerase III subunit D (polr3d) & Parambassis ranga & $7 e-62$ & MN747821 \\
\hline SSH\#75_1 & Genetic suppressor element 1 & Neolamprologus brichardi & $3 e-69$ & MN747820 \\
\hline SSH\#77_1 & Enolase 1 alpha (eno1) & Mylandia zebra & $2 \mathrm{e}-92$ & MN747818 \\
\hline SSH\#78_1 & Cyclic-AMP dependent transcription factor 4 (ATF4) & Oreochromis niloticus & $9 e-47$ & MN876861 \\
\hline SSH\#79_1 & NACHT, LRR and PYD domains-containing protein 14 & Echeneis naucrates & $9 e-60$ & MN747817 \\
\hline SSH\#80_1 & L-rhamnose-binding lectin & Haplochromis burtoni & $5 e-21$ & MN876856 \\
\hline SSH\#82_1 & E3 ubiquitin-protein ligase RNF12-B & Neolamprologus brichardi & $1 e-105$ & MN876857 \\
\hline SSH\#88_1 & Aldo-keto reductase family 1 member A1 (akr1a1) & Archocentrus centrarchus & $2 \mathrm{e}-67$ & MN876858 \\
\hline SSH\#2_2 & 60s Ribosomal protein L36 (rpl36) & Oreochromis aureus & $4 \mathrm{e}-79$ & MN747810 \\
\hline SSH\#45_1 & 18s Ribosomal rRNA gene & Etroplus suratensis & $1 e-130$ & MN837624 \\
\hline SSH\#62_1 & Ribosomal protein L13a (rp|13a) & Oreochromis aureus & $9 e-101$ & MN747821 \\
\hline SSH\#66_1 & 60s Ribosomal protein L26 (rp|26) & Oreochromis aureus & $2 e-122$ & MN854096 \\
\hline SSH\#86_1 & Ribosomal protein L13 (rpl13) & Oreochromis niloticus & $6 e-72$ & MN876859 \\
\hline SSH\#53_1 & Cytochrome P450 1A (CYP1A) & Archocentrus centrarchus & $2 \mathrm{e}-50$ & MN854089 \\
\hline SSH\#59_1 & 40s Ribosomal protein S25 (rps25) & Oreochromis aureus & $2 \mathrm{e}-92$ & MN854093 \\
\hline SSH\#60_1 & Hypothetical protein ES05CMFRI_AKTV & Oreochromis aureus & $3 e-69$ & MN854094 \\
\hline SSH\#67_1 & Cytochrome P450 1A (CYP1A) & Archocentrus centrarchus & $2 e-62$ & MN854097 \\
\hline SSH\#76_1 & NLRC3-like protein & Oreochromis niloticus & 2e-114 & MN747819 \\
\hline SSH\#84_1 & Ribosomal protein L13a (rpl13a) & Oreochromis aureus & $1 e-120$ & MN876860 \\
\hline
\end{tabular}




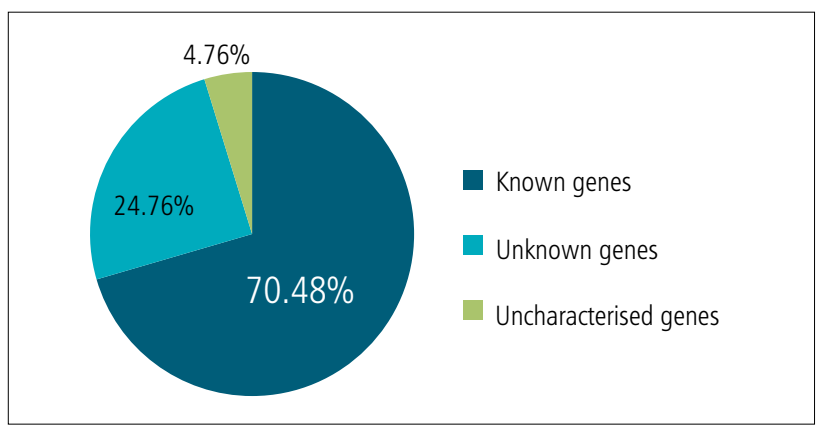

Fig. 1. EST classification representation in subtracted library

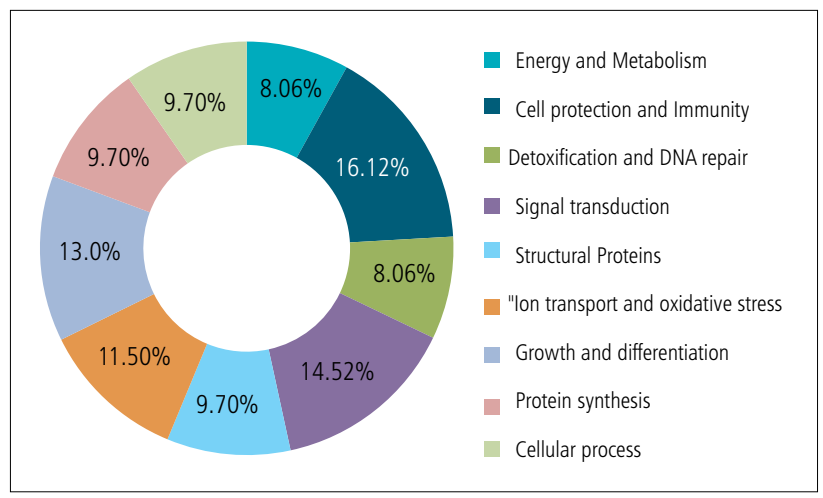

Fig. 2. Distribution of genes screened from SSH library of $E$. suratensis challenged with SW (36\%). The genes were categorized under different groups according to predicted function.

oxidoreductase subunit etc. Immunity genes such as Serine/Threonine phosphatase and MHC's were also present. L-Rhamnose binding lectin (RBL), RbBPI bactericidal permeability ceasing protein which has bactericidal property and oxysterol binding protein for lipid transport were also identified.

\section{Validation of selected SSH EST's by qPCR}

Aldo-keto reductase family 1 plays a crucial role in oxidative stress, the expression reduced nearly 0.6 fold when the fish adapted to

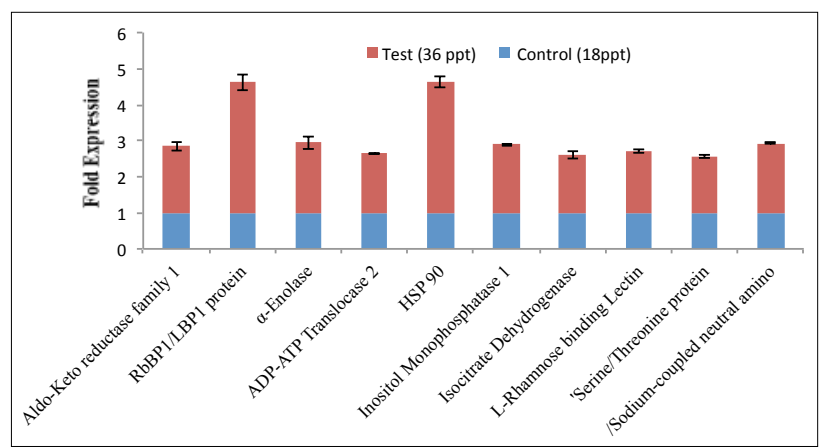

Fig. 3. Effect of SW (36\%) acclimation on expression of selected genes from SSH library in E. suratensis gills. Expression level at 36\% was normalised with expression level of 18\%o (ctrl). Each independent experiment was performed at least in triplicates $(n=3)(p<0.05$, one way ANOVA). freshwater and expression increased nearly 0.9 fold in the fish adapted to sea water when compared to control (18\%). As compared to FW, SW expression was 1.5 fold more ( Fig. 3\&4). $\mathrm{RbBP1} / \mathrm{LBP} 1$ protein are endotoxin-binding proteins that function in a coordinated manner to facilitate an integrated host response to invade Gram-negative bacteria, here the FW acclimatised ( $0 \%$ o) fishes gave comparatively less expression, it was 0.7 fold less and in SW acclimated it was 2.6 fold more when compared to the control and 3.5 fold, increase when compared with FW. -Enolase, ADP-ATP translocase 2 are cytosolic enzymes which showed 0.35 fold and 0.65 fold, reduction respectively in FW. Both the genes showed 0.7 fold, increase in SW expression with respect to control whereas 1.2 fold, increase when compared with FW. HSP 90, a chaperon protein that helps in proper protein folding and with important roles in environmental stresses, showed increased expression level in FW acclimatized fishes, the fold increase was 0.35 and fold increase was 2.6 in SW adapted animal when compared to control and 2.3 fold, increase with respect to FW, as adapting to SW and FW required more HSP 90 than control. Inositol monophosphatase 1 (IMPA1) and L-Rhamnose binding lectin (RBL) showed a serious drop in their expression level in FW animal i.e. nearly 0.8 fold, reduction whereas $\mathrm{SW}$ adapted fishes showed an increase in their expression level i.e. nearly 0.75 fold with respect to control and 1.7 fold with respect to FW. Isocitrate dehydrogenase expression showed a decrease in FW i.e. about 0.6 fold with respect to control and in SW an increase by 0.6 fold when compared with control and 1.20 fold with respect to FW acclimated fish. Serine/ Threonine protein phosphatase 2A had a significant drop in expression at FW by 0.8 fold and 0.60 fold, increase in SW with respect to control and an increase in expression level of 1.4 fold with respect to FW. A tremendous decrease in sodium-coupled neutral amino acid transporter 2 (snat2) expression was expected, the reduction in terms of fold was 0.80 in FW and in SW adapted fish it showed an increase of 0.93 fold when compared to control and showed 1.7 fold, increase with respect to FW.

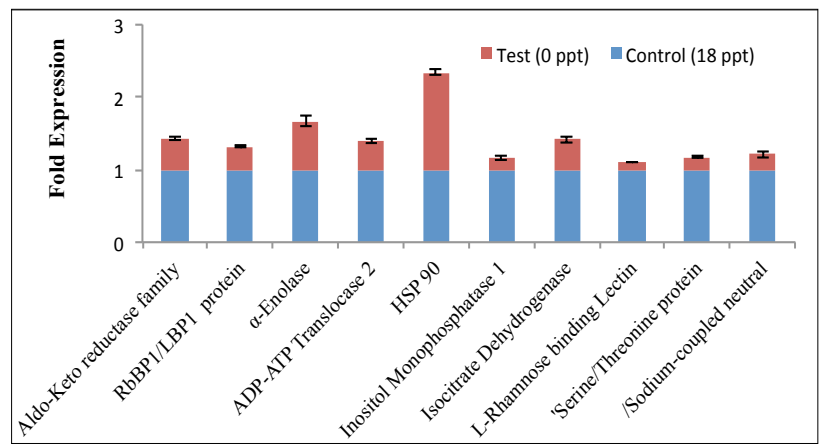

Fig. 4. Effect of FW $(0 \%$ ) acclimation on expression of selected genes from SSH library in $E$. suratensis gills. Expression level at $0 \%$ owas normalised with expression level of $18 \%$ o (ctrl). Each independent experiment was performed at least in triplicates $(n=3)(p<0.05$, one way ANOVA). 


\section{Discussion}

Among teleost species, $95 \%$ are stenohaline and complete their life cycle either in freshwater or saline water. The remaining $5 \%$ are euryhaline and have the capacity to adapt the change in environmental salinities (Tang and Lee, 2007). Physiological changes in them are driven by regulations of gene expression that can be analysed and characterised using different techniques. It is possible to explain theoretically how the organism responds to fluctuations in the external environment at the molecular level. Getting an idea of how an organism responds to changes in the external environment helps to understand the genes involved in switching on/off or those that are up and down regulated during salinity changes. The current study was designed not only to generate a catalogue of genes that were differentially expressed in the target species in response to different salinity conditions but also to investigate and identify the mRNA expression profile that control the adaptive response. In European eel, Anguilla anguilla it was found that after SW acclimation, mRNA expression of branchial NKCC increased (Cutler and Cramb, 2002). Similar to NKCC, CFTR protein is expressed only in gills of SW acclimated fishes to secrete excess $\mathrm{Cl}$ for homeostasis (Tang and Lee, 2007). In this investigation genes involved in salinity tolerance were classified based on annotation results and published studies. Type I included genes responsible for ion-transportation, which are found to be upregulated under elevated salinity, balancing ion homeostasis and osmolytes recirculation. Type II genes contribute to overall energy metabolism during salinity acclimation. Type III, genes responsible for structural protein that controls the rearrangement of cytoskeletal structures which enables cells for the acclimation to hyper and hypo saline condition. Type IV genes are involved in signal transduction activities that provide necessary information to the cells according to the changes in the environment. Type $V$ genes have specific role and are responsible for protection and immune system mechanism in cell. These genes help cells to protect from damage caused due to salinity fluctuations and to recover their functionality. Type VI genes help the cell in detoxification, potentially from the chemicals present in the water along with other ions.

In a study related to functional genomics on migration of wild salmon, it was found that ADP-ATP translocase 2 associated with oxidative stress was significantly upregulated in muscles (Miller et al., 2009). Similarly, in this study the fold increase in expression was 0.7 with respect to control $(18 \%$ ) in SW but in FW the gene expression was reduced ( 0.65 fold), whereas when compared with FW, SW adapted fish exhibited an increase in expression of ADP-ATP translocase 2 which was 1.2 fold. -Enolase, a glycolytic enzyme which catalyse the synthesis of 2-Phosphoglyceratewas seen upregulated in SW ( 0.7 fold) and down-regulated in FW ( 0.35 fold) when compared with control, while in SW acclimated animal the expression increased to 1.2 fold when compared with FW adapted E. suratensis. -Enolase is also being widely studied for its excess production to survive hypoxia and other cellular stress (Fiol et al., 2006). In another study in Sparus aurata brain enolase is referred to as a potential biomarker for stress response in fish under stressful conditions (Eissa and Wang 2016). When euryhaline fishes are acclimated to SW, a significant rise in plasma osmolality occurs as compared to fishes acclimated to FW (Seale et al., 2003). Homeostasis of plasma osmolality is achieved by increasing the myo-inositol concentration which correspondingly increases the activity of the enzyme involved in myo-inositol synthesis. Increase in the expression level of Inositol monophosphatase (IMPA1) and myo-inositol phosphate synthase (MIPS) at mRNA and protein level depends on the inorganic ion concentration and pH (Villareal and Kultz, 2014). Study in Oreochromis mossambicus had shown significant increase in IMPA1 protein under hyperosmotic condition after $72 \mathrm{hrs}$. IMPA1 was upregulated after $24 \mathrm{hrs}$ post hyperosmotic stress (Xiaodan Wang and Dietmar Kultz, 2017), similarly in this study IMPA1 exhibited an expression increase of 0.75 fold in SW acclimated animal with respect to control and 1.7 fold with respect to FW. RbBPI/LBPI which belongs to the family of AMPs (Antimicrobial proteins) has been isolated from a wide range of teleost fishes. The characterization and differential expression of RbBPI/LBPI in response to several immune-stimulants and bacteria has been studied (Lee et al., 2017). The up-regulation of RbBPI/LBPI in $E$. suratensis indicates their role in the immune system. In this study RbBPI/LBPI was found to be up-regulated ( 2.6 fold with respect to control) in SW and was found down regulated in FW ( 0.7 fold, reduction with respect to control), whereas with respect to FW, SW acclimated fish displayed an expression hike of 3.5 fold. This data indicates that RbBPI/LBPI other than having anti-microbial activity is also functionally involved in physiological stress response.

Osmotic challenges are attained by several ion transporters and ion transport channels which require a large amount of energy (Tseng and Hwang, 2008). In our present study isocitrate dehydrogenase which is involved in TCA cycle is upregulated in SW (0.6 fold with respect to control and 1.2 fold with respect to FW adapted fish), this enzyme located in mitochondria catalyse the oxidative decarboxylation of isocitrate to produce $\alpha$-ketoglutaric acid, $\mathrm{CO}_{2}$ and $\mathrm{NADH}$, providing energy for organisms and biosynthetic precursors. Heat Shock Proteins (HSPs) also known as stress proteins, are constitutively expressed in cells and are involved in protein folding (chaperones), stability, assembly and localization (Iwama et al., 2006). Evidence is available that shows there occurs an increase in HSP accumulation in cells to survive 
in normal as well as after stress exposure. Increase in HSP expression represents a remarkable molecular mechanism to adapt with stress although the animal exhibits its own responses with varying thresholds of sensitivity (Hoffmann, 1999). Here HSP 90 was upregulated in SW and FW as compared to control where the former had 2.6 fold and the later 0.35 fold, increase in expression indicating their role in both hyper and hypo salinity adaptations, but when compared with FW, SW adapted fish revealed 2.3 fold, increase. Aldo-keto reductase family is known to be the superfamily of enzymes involved in the reduction of carbonyl groups to its respective alcohols. This group of enzymes are used as biomarkers to monitor oxidative stress. Ubiquitous behaviour of such enzymes including its metabolism of activated carbonyl groups gives an idea that it has a significant role in xenobiotic as well as endogenous compound detoxification (Almroth, 2008). In our study Aldo-Keto reductase enzyme were upregulated in SW by 0.9 fold and down regulated in FW by 0.6 fold with respect to control and when compared with FW, SW adapted fish displayed upregulation of 1.5 fold. This slight increase in expression of this family of enzyme also implicates its role in oxidative stress. L-Rhamnose binding lectin (RBLs) has been isolated from various invertebrates and fishes describing their role in various inflammatory responses with special mention to the innate immunity. Watnabe et al in 2009 proposed that different pathogens are recognised by RBLs at the site of inflammation through blood circulation where it binds on the surface of leukocyte to enhance phagocytosis. Involvement of RBLs in cytotoxicity, fertilization control and carbohydrate metabolism also has been proposed. Expression level of RBLs in fish acclimated to SW showed an increase of 0.75 fold and FW a reduction of 0.8 fold with respect to control, whereas with reference to FW, SW acclimated fish expression was 1.7 fold more which is similar to $E$. suratensis immune and stress response as in the case of RbBPI/LBPI gene. Serine/threonine protein phosphatase $2 \mathrm{~A}$ known to be expressed in all eukaryotic cells is involved in a wide range of cellular functions such as metabolism, protein synthesis, cell-division, apoptosis and regulatory role in membrane receptors (Ceulemans and Bollen, 2004) with special reference to oxidative stress signalling (ROS related signalling). Functionally protein phosphatases are having a catalytic portion and a regulatory portion in which the catalytic component is highly conserved as compared to regulatory component (Shi, 2009). Regulatory components are affected by inhibitors including environmental stress (Mathe et al., 2019). Also a study in mummichog (Fundulus heteroclitus) revealed that protein phosphatases (PP1), under which serine/threonine protein phosphatase $2 \mathrm{~A}$ comes are closely related to NKCC transporters (active transport system responsible for transporting $\mathrm{Na}^{+}, \mathrm{K}^{+}$and $\mathrm{Cl}$ into the cell) (W.S Marshall, 2010). In E. suratensis adapted to FW, 0.8 fold, reduction in expression of serine/threonine protein phosphatase was observed whereas SW adapted showed 0.6 fold, increase as compared to control and with respect to FW, SW expression increased 1.4 fold. Sodium-coupled neutral amino acid transporter 2 (snat2) belonging to solute carrier family mediates the movement of bulky neutral amino acids across the cell membrane against the inward movement of sodium down its electrochemical gradient (Barid et al., 2009). In euryhaline fishes, salinity acclimation results in an increase of cortisol in cells (McLean et al., 1997) which may be due to the upregulation of snat2. Neutral amino acids may be functioning as compatible osmolytes in cells which are hypertonically stressed. Present study showed an increase of 0.9 fold and 0.8 fold, reduction of snat2 expression in SW and FW acclimatized E. suratensis as compared to control and with respect to FW, snat2 expression was 1.7 fold more in SW adapted fish.

The validation result of $q P C R$ indicates that the SSH data is reliable and accurate, both observations of SSH and qPCR are limited to transcriptional level and provides information for future studies aimed at characterizing and comparing the role of salinity regulated genes in non-osmoregulatory organ and osmoregulatory organ during salinity adaptations. The differentially expressed salinity regulated genes identified in this study are associated with ion transporters and metabolites, signal transduction, energy metabolism, structure reorganization and immune response suggesting the important role of gills for osmoregulation and salinity adaptation. Most of the genes related to stress response found to be involved in other aspects like cell defence, metabolism, growth and differentiation etc. Genes upregulated in gill tissue may function as potential osmosensors. The catalogue of differentially expressed genes identified, as well as their expression pattern at different salinities provides more information regarding the molecular mechanisms of osmoregulation and salinity adaptation as well as stress response of aquatic species towards salinity.

Further, current investigation was successful in identifying differentially expressed genes in a brackishwater fish, E. suratensis by SSH in response to high salinity stress $(36 \% 0)$. We could also identify the significant up-regulation in transcription-level expression of several genes in gills in response to SW acclimation.

\section{Acknowledgements}

The authors are thankful to the Director, ICAR-Central Marine Fisheries Research Institute, Ernakulam for providing necessary facilities. The use of fish and experiments were approved by the Institute Research Committee. We also thank Dr. Joel James, University of Arizona for his valuable comments on earlier drafts of the manuscript. 


\section{References}

Almroth, B. C. 2008. Oxidative damage in fish used as biomarkers in field and laboratory studies. Dissertation, Gothenburg University, Sweden. 17 pp.

Arun Kumar, T. V., M. A. Pradeep, S. R. Krupesha Sharma, N. K. Sanil, K. K. Vijayan and E. S. Anooj. 2020. Differential morphological responses to osmotic changes in euryhaline cichlid, Etroplus suratensis (Bloch, 1790). Eurasia. J. Biosci., 14: 10271033

Barid, F. E., K. J. Bett, C. MacLean, A. R. Tee, H. S. Hundal and P. M. Taylor. 2009. Teritary active transport of amino acids reconstituted by co-expression of system A and L transporters in Xenopus oocytes. Am. J. Physiol. Endocrinol. Metab., 297: E822-E829.

Ceulemans, H. and M. Bollen. 2004. Functional diversity of protein phosphatase-1, a cellular economizer and reset button. Physiol. Rev., 84: 1-39.

Chandrasekar, S., T. Nich, G. Tripathi, N. P. Sahu, A. K. Pal and S. Dasgupta. 2014. Acclimation of brackishwater pearl spot (Etroplus suratensis) to various salinities: relative changes in abundance of branchial $\mathrm{Na}^{+} / \mathrm{K}^{+}$-ATPase and $\mathrm{Na}^{+} / \mathrm{K}^{+} / 2 \mathrm{Cl}$ co-transporter in relation to osmoregulatory parameters. Fish. Physiol. Biochem., 40: 983-996.

Cutler, C. P. and G. Cramb. 2002. Two isoforms of the $\mathrm{Na}+/ \mathrm{K}+/ 2 \mathrm{Cl}$ - cotransporter are expressed in the European eel (Anguilla Anguilla). Biochem. Biophys. Acta., 1566: 92-103.

Diatchenko, L., C. Lauyf, A. P. Campbell, F. Moqadam, B. Huang, S. Lukyanov, K. Lukyanov, N. Gurskaya, E.D. Sverdlov and P.D. Siebert. 1996. Suppression subtractive hybridization: a method for generating differentially regulated or tissue-specific cDNA probes and libraries. Proc. Natl. Acad. Sci. U.S.A., 93: 60256030.

Diatchenko, L., S. Lukyanov, Y. F. Lau and P. D. Siebert. 1999. Suppression subtractive hybridization: a versatile method for identifying differentially expressed genes. Methods. Enzymol., 303: 349-380.

Eissa, N. and H. P. Wang. 2016. Transcriptional stress responses to environmental and husbandary stressors in aquaculture species. Rev. Aquacult., 8: 61-88.

Evans, D. H., P. M. Piermarini and K. P. Choe. 2005. The multifunctional fish gill: dominant site of gas exchange, osmoregulation, acid-base regulation, and excretion of nitrogenous waste. Physiol. Rev. 85: 97-177.

Fiol, D. F., S. Y. Chan and D. Kultz. 2006. Identification and pathway analysis of immediate hyperosmotic stress responsive molecular mechanisms in Tilapia ( 0 . mossambicus) gill. Comp. Biochem. Physiol. Part D., 1: 344-356.

Hirose, S., T. Kaneko, N. Naito and Y. Takei. 2003. Molecular biology of major components of chloride cells. Comp. Biochem. Physiol. Part B., 136: 593-620.

Hoffmann, G. E. 1999. Ecologically relevant variation induction and function of heat shock proteins in marine organisms. Am. Zool., 39: 889-900.

Holmes, W. N. and E. M. Donaldson. 1969. The body compartments and the distribution of electrolytes. In: W.S. Hoar and D.J. Randall (Eds.) Fish physiology, Vol. 1. San Diego, CA: Academic Press. 1-89 p.

Iwama, G. K., L. O. B. Afonso and M. M. Vijayan. 2006. Stress in fish. In: D.H. Evans and J.B. Clairborne (Eds.) The physiology of fishes. Boca Raton, FL: CRC press. 319-342 p.

Lee, S., D. A. S. Elvitigala, S. Lee, H. C. Kim, H. C. Park and J. Lee. 2017. Molecular characterization of bactericidal permeability increasing protein/ lipopolysaccharide binding protein from black rockfish (Sebastes Schlegelii): Deciphering its putative antibacterial role. Dev. Comp. Immunol., 67: 266-275.
Maetz, J. 1974. Aspects of adaptation to hypo-osmotic and hyper-osmotic environments. In: D.C. Malins and J. R. Sargent (Eds.) Biochemical and biophysical perspectives in marine biology. New York: Academic Press. 1-167 p.

Marshall, W. S. 2010. Mechanosensitive signalling in fish gill and other ion transporting epithelia. Acta. Physiologica., 202(3): 487-499.

Marshall, W.S. and T.D. Singer. 2002. Cystic fibrosis transmembrane conductance regulator in teleost fish. Biochem. Biophys. Acta., 1566: 16-27.

Mathe, C., T. Garda, C. Freytag and M. M. Hamvas. 2019. The role of serine-threonine protein phosphatase PP2A in Plant oxidative stress signalling- Facts and hypothesis. Int. J. Mol., 20 (12): 3028.

McLean, E., R. H. Delvin, J. C. Byatt, W. C. Clarke and E. M. Donaldson. 1997. Impact of a controlled release formulation of recombinant bovine growth hormone upon growth and seawater adaptation in coho (Oncorhynchus kisutch) and chinook (Oncorhynchus tshawytscha) salmon. Aquac., 156: 113-128.

Menon, M. D., R. Sreenivasan and B. Krishnamurthi. 1959. Report to the Indian council

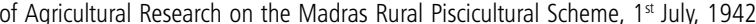
to 31 March, 1952. Madras Government Press. 171 pp.

Miller, K. M., A. D. Schulze, N. Ginther, S. Li, D. A. Patterson, A. P. Farrel and S. G. Hinch. 2009. Salmon spawning migration: Metabolic shift and environmental triggers. Comp. Biochem. Physiol, Part D., 4: 75-89.

Padmakumar, K. G. L. Bindu and P.S. Manu. 2012. Etroplus suratensis (Bloch), the state fish of Kerala. J. Biosci., 37: 925-931.

Pfaffl, M. W. 2001. A new mathematical model for relative quantification in real-time RT-PCR. Nucleic. Acids. Res., 29 (9): e45.

Seale, A.P., N.H. Richman, T. Hirano, I. Cooke and E.G. Grau. 2003. Cell volume increase and extracellular $\mathrm{Ca}^{2+}$ are needed for hypo-osmotically induced prolactin release in Tilapia. Am. J. Physiol. Cell. Physiol., 284: C1280-C1289.

Shi, Y. 2009. Serine/Threonine phosphatase: Mechanism through structures. Cell., 13: 468-484.

Tang, C. H. and T. H. Lee. 2007. The effect of environmental salinity on the protein expression of $\mathrm{Na}^{+} / \mathrm{K}^{+}$-ATPase, $\mathrm{Na}^{+} / \mathrm{K}^{+} / 2 \mathrm{Cl}^{-}$co-transporter, cystic fibrosis transmembrane conductance regulator, anion exchanger 1 , and chloride channe 3 in gills of euryhaline teleost, Tetraodon nigroviridis. Comp. Biochem. Physiol. Part A., 147: 521-528.

Tseng, Y. and P. Hwang. 2008. Some insights into energy metabolism for osmoregulation in fish. Comp. Biochem. Physiol. C. Toxicol. Pharmacol., 148(4): 419-429.

Villareal, F. and D. Kultz. 2015. Direct ionic regulation of the activity of myo-inosito biosynthesis enzymes in Mozambique Tilapia. PLOS ONE., 10(6): e0123212.

Wang, X. and D. Kultz. 2017. Osmolality/ salinity responsive enhancers (OSRE's) control induction of osmoprotective in euryhaline fish. Proc. Natl. Acad. Sci. U.S.A., E2729-E2738.

Watanabe, Y., H. Tateno, S. Nakamura-Tsuruta, J. Kominami, J. Hirabayashi, 0. Nakamura, T. Watanabe, H. Kamiya, T. Naganuma, T. Ogawa, R. J. Naude and K. Muramoto. 2009. The function of rhamnose-binding lectin in innate immunity by restricted binding to Gb3. Dev. Comp. Immunol., 33: 187-197.

Xie, Y. S., F. H. Li, D. D. Wang, H. Jiang, C. S. Zhang, K. J. Yu and J. H. Xiang. 2010. Screening of genes related to ovary development in Chinese shrimp Fenneropenaeus chinensis by suppression subtractive hybridization. Comp. Biochem. Physiol. D., 5: 98-104. 